\title{
SistemAS DE OPTIMIZACIÓN DE PRECIOS Y RENTABILIDAD (OPR)
} EN RESTAURANTES*

\author{
Julio Padilla Solís \\ Alberto Cossa Cabanillas \\ Facultad de Ingeniería de Sistemas, Universidad de Lima \\ jpadilla@ulima.edu.pe, jcossa@ulima.edu.pe
}

\section{Resumen}

Los sistemas de OPR en restaurantes incorporan los conceptos de RevPash y Menu Engineering para soportar las siempre difíciles decisiones sobre los precios, las promociones y la administración de recursos. En el presente trabajo se explican dichos conceptos para luego demostrar el beneficio de su correcta utilización en dos indicadores de gestión: contribución marginal y duración del servicio. Sobre la base de un simulador de restaurantes especialmente desarrollado para esta investigación, se diseñan experimentos que demuestran la facilidad y los beneficios que pueden obtenerse con el uso de estos sistemas. Se trata de mejoras en la gestión de restaurantes que deben difundirse para ventajas de propietarios y clientes.

Palabras clave: optimización / gestión de restaurantes / revenue management

* Agradecemos a los alumnos Guillermo Zevallos Luna Victoria y Juan Pablo Peche Altez por su importante colaboración en la elaboración de este trabajo.

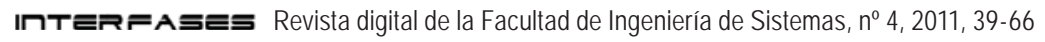




\section{Introducción}

En la gestión de un restaurante surge la necesidad de tomar determinadas decisiones, que no siempre tienen una respuesta inmediata, por ejemplo: ¿cuál es el precio que se debe cobrar por cada plato?, ¿qué margen de contribución deja cada plato?, ¿cuándo y en qué platos se deben hacer promociones?, ¿se deben ofrecer descuentos en ciertas horas del día o en ciertos días de la semana?, ¿cuál es la capacidad de atención que se debe ofrecer a la demanda?, o ¿qué conviene más, que un cliente desocupe una mesa o que consuma más?

Las respuestas a estas y otras preguntas se complican aún más si tenemos en cuenta que existe incertidumbre en la cantidad de clientes que vendrán al restaurante, en el tamaño de los grupos de comensales y el tiempo que tendrán ocupadas las mesas. Los sistemas de OPR ofrecen una forma estructurada y sistemática de responder a estas interrogantes por medio de procesamientos computacionales de los datos, de modelos matemáticos y de procedimientos de gestión adecuados.

\section{Arquitectura de un sistema informático para un restaurante}

Un restaurante, o una cadena de restaurantes, tiene que satisfacer sus necesidades de información tanto en los puntos de venta como en todo el proceso logístico para poder atender su demanda. Por ello, en la figura 1 mostramos tres niveles interrelacionados de información. El nivel inferior es el de ejecución de operaciones. Con el fin de que los puntos de venta puedan recibir un cliente, tomar el pedido, prepararlo y servirlo, deben ser abastecidos con todos los ingredientes correspondientes, además de los utensilios del caso. Ese abastecimiento conforma una cadena logística de compras, transformación (preparación de salsas, porcionado de carnes, corte de papas, etcétera) y abastecimiento al punto de venta. Para que ese nivel trabaje adecuadamente se necesita el segundo nivel, que es el de planeamiento. Todo planeamiento es una apuesta a un futuro que tiene que predecirse por medio de un pronóstico de ventas. Sobre esta base se planifica el abastecimiento a los puntos de ventas, que generalmente ven muy reducida su capacidad de almacenamiento tanto por el espacio que ocupa como por la condición de perecibles de muchos ingredientes. Esto obliga a establecer sistemas de capacidad finita de corto plazo. Igualmente, los procesos de transformación y compras requieren planearse $y$, dependiendo de la exigencia en cuanto a capacidades de estos dos procesos, se necesitará también un sistema de capacidad finita o un simple sistema transaccional. 
Estas labores de ejecución y de planeamiento de la ejecución responden a decisiones tomadas en base a la experiencia y el conocimiento del negocio, pero muchas veces carecen de estructuración y desperdician oportunidades de mejora que no se vislumbran sin un análisis sistémico del negocio. Las técnicas de OPR tienen como objetivo soportar estas decisiones y conforman el tercer nivel, que es el de gestión integrada sobre el cual detallaremos conceptos.

\section{Arquitectura del modelo de gestión propuesto}

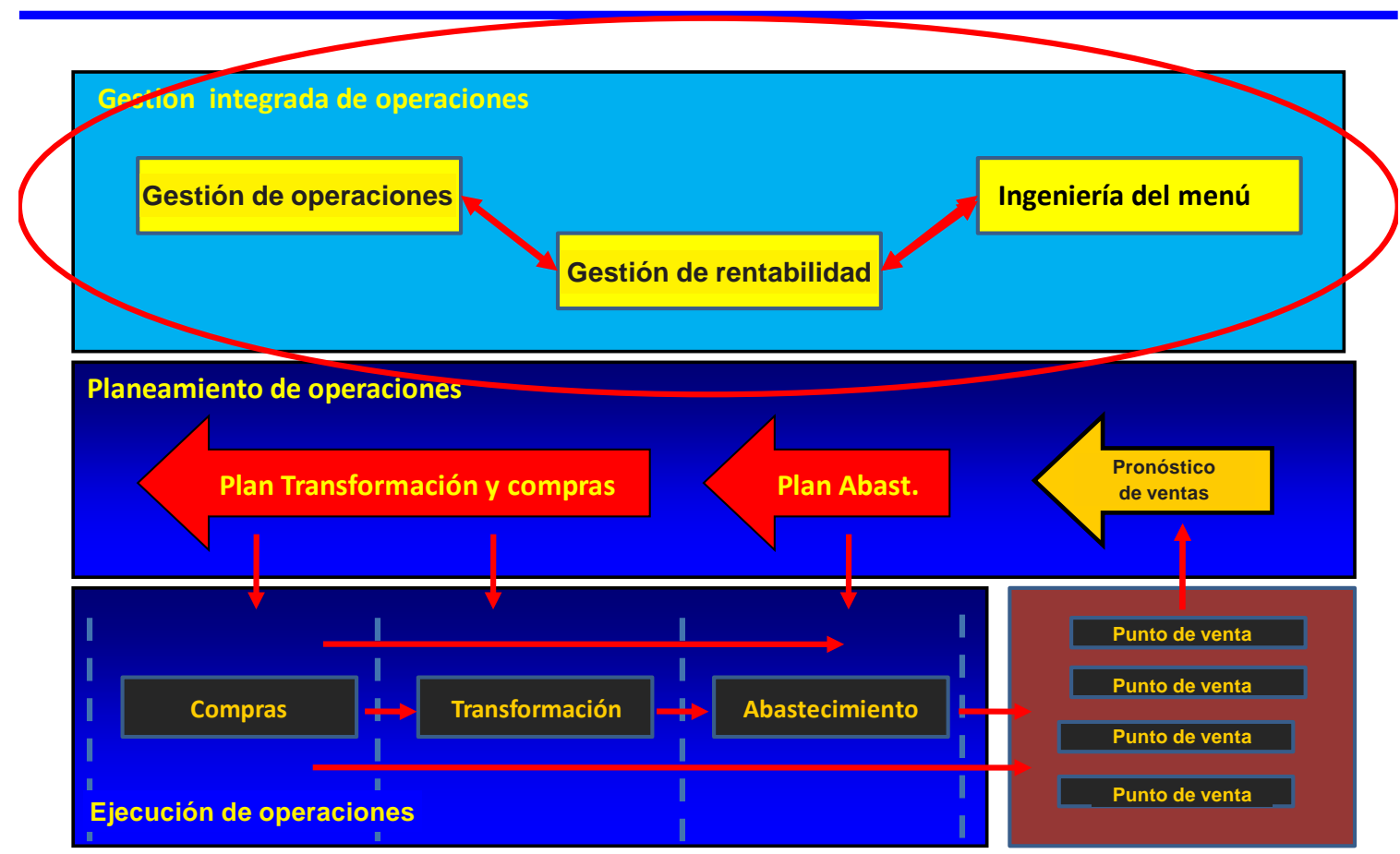

Figura 1. Arquitectura del modelo de restaurante propuesto 


\section{Gestión de rentabilidad}

La gestión de rentabilidad en restaurantes viene usando una serie de indicadores; los más populares son los siguientes:

- Ticket promedio.- Es la facturación promedio por cliente.

- Porcentaje de mano de obra en el costo total.- Al ser generalmente la mano de obra uno de los costos importantes de un restaurante, es muy natural que una gestión use un indicador de este tipo.

- Porcentaje de gastos de alimentos en el costo total.- Bajo el mismo criterio del indicador anterior.

- Índice de ocupación.- Muestra el porcentaje promedio de ocupación de mesas o sillas en el restaurante.

Un restaurante es una combinación de venta de platos y de tiempo en la ocupación de su capacidad. Si se resalta la característica de que las horas de venta de los restaurantes están limitadas por las costumbres de los horarios de las comidas de la sociedad en que trabaja, no podemos juzgar la rentabilidad sin tomar en cuenta el factor tiempo. Evidentemente, el otro factor de rentabilidad es la venta misma de los platos. Ninguno de los indicadores expuestos combina los dos factores. En ello está la primera propuesta de los sistemas OPR: el indicador RevPash (revenue per available seat hour) (Thompson y Sohn 2008). Se trata de medir el ingreso o la contribución marginal por unidad de capacidad-tiempo. La capacidad típica de un restaurante es vista como las sillas disponibles para sus clientes, pero no siempre lo es. La capacidad puede estar establecida por el número de mesas, la cocina, la atención de los mozos, etcétera. En todos los casos el indicador responde correctamente. La determinación adecuada de cuál es el recurso limitante requiere de lo que se ha presentado como gestión de operaciones, que se analizará más adelante. El factor tiempo queda incorporado al calcular el indicador por lapsos de una hora, media hora o cuarto de hora. En general, lo que se construye es un mapeo del indicador por periodos y en todos los días de la semana. Una vez construidos estos mapas, se observan zonas de bajo RevPash (zonas frías) o de altos RevPash (zonas calientes), las cuales guían las acciones tácticas en cuanto a precios, capacidades y tiempos que deben efectuar los administradores del restaurante. Una idea de estos conceptos se ve en la figura 2. 


\section{Proceso de gestión de rentabilidad en la operación}

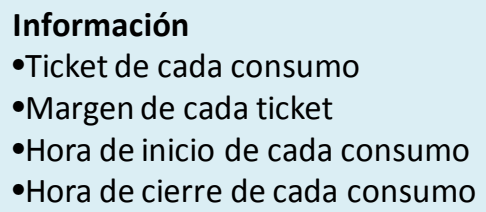

\begin{tabular}{|c|c|c|c|c|c|}
\hline & $11: 30$ & $12: 00$ & $12: 30$ & 13:00 & \multirow{4}{*}{$\begin{array}{l}\text { - Periodos de RevPash altos } \\
\text { - Subir precios } \\
\text { - Reducir duración del } \\
\text { servicio }\end{array}$} \\
\hline Lunes & 2.39 & 6.72 & 6.43 & 6.36 & \\
\hline Martes & 0.19 & 2.91 & 2.92 & 3.52 & \\
\hline Miérc. & 0.61 & 2.96 & 5.46 & 4.61 & \\
\hline Jueves & 0.75 & 2.70 & 3.92 & 4.29 & \\
\hline Viernes & 0.22 & 1.47 & 4.86 & 3.37 & \\
\hline Sábado & 1.49 & 6.04 & 8.76 & 8.17 & \\
\hline Dom. & 2.72 & 6.22 & 11.89 & 12.60 & \\
\hline
\end{tabular}

Figura 2. Datos de entrada para el cálculo del RevPash y las acciones consecuentes

a) Cálculo del RevPash

El cálculo del RevPash consiste en dividir todos los tickets consumidos durante un periodo de tiempo entre la capacidad (sillas) disponible. Un ticket consumido durante varios periodos de tiempo debe ser prorrateado entre ellos en función de los minutos que le correspondan. El valor del RevPash para cada periodo se obtiene sumando todas las fracciones de tickets correspondientes al periodo y dividiendo este total entre la capacidad disponible. En la figura 3 se muestra un ejemplo del cálculo. Los periodos son de 30 minutos, para los cuales el encabezado muestra el inicio del periodo. El ejemplo asume una capacidad de 15 sillas disponibles como recurso limitante. En el valor del ticket se puede considerar la facturación misma o el margen de contribución restando el costo variable de lo consumido. El margen de contribución es la verdadera rentabilidad del restaurante y por ello recomendamos su uso. 


\begin{tabular}{|clll|}
\hline Ticket & Valor (S/.) & Hora inicio & Hora fin \\
\hline 1 & 64.00 & $11: 40$ & $12: 20$ \\
2 & 120.00 & $11: 50$ & $12: 40$ \\
3 & 80.00 & $12: 10$ & 12.50 \\
4 & 118.00 & $12: 20$ & $13: 25$ \\
\hline Total & 382.00 & & \\
Capacidad & 15 sillas & & \\
RevPash & & & \\
\hline
\end{tabular}

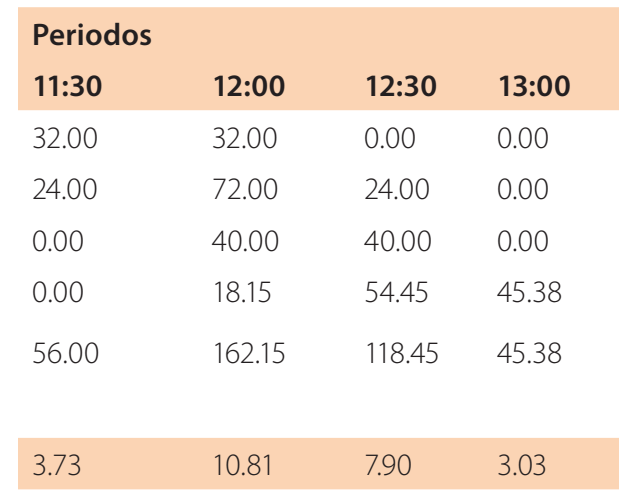

Cuadro 1. Ejemplo detallado para el cálculo del RevPash

Todos los cálculos mostrados en este artículo han sido efectuados mediante el uso de un software especialmente desarrollado para el cálculo del RevPash y del Menu Engineering con total flexibilidad para definir las fechas de los tickets a considerar, los lapsos para el cálculo del indicador y la capacidad disponible.

b) Acciones para manejar los precios

Las acciones típicas para manejar los precios en un restaurante están categorizadas de la siguiente manera (Kimes 2008):

- Especiales por hora del día.

- Promociones especiales del menú.

- Precios según parte del día.

- Precios según día de la semana.

- Promoción de bebidas y postres por mozos.

- Descuentos por tamaño del grupo o por tipo de cliente (grupos de afinidad).

Estas acciones para bajar los precios son necesarias en zonas de bajo RevPash. La duda está en qué platos se deben efectuar las promociones y cuánto debe debe ser el monto de los descuentos. Para contestar estas interrogantes se requiere de una ingeniería del menú que se expondrá más adelante. En las zonas de alto RevPash las acciones correctas son subir el precio, que en realidad se trata de eliminar descuentos y promociones.

c) Acciones para manejar la duración del servicio

El proceso que pasa un cliente durante toda la atención de un restaurante ha sido perfectamente definido por Kimes (2008). El proceso tiene seis etapas:

- Prearribo: desde que el cliente decide ir al restaurante hasta que llega.

- Postarribo: desde que el cliente llega al restaurante hasta que se sienta en una mesa. 
- Preproceso: desde que el cliente se sienta hasta que recibe su primera orden.

- En proceso: desde que el cliente recibe su primera orden hasta que pide la cuenta.

- Posproceso: desde que el cliente pide su cuenta hasta que sale del restaurante.

- Preparación de mesa: desde que el cliente sale hasta que la mesa es ocupada nuevamente.

Todo procedimiento para disminuir tiempos en cualquiera de las etapas es una acción correcta en zonas de alto RevPash. La tecnología disponible en la actualidad ha dado lugar a muchos dispositivos, principalmente inalámbricos, que permiten soportar procedimientos más eficientes. Otra forma de disminuir los tiempos es mediante más recursos, cuya incorporación es tema de la gestión de operaciones.

\section{Ingeniería del menú (Menu Engineering)}

El concepto de ingeniería del menú proviene del término Menu Engineering creado por Kasavana (1990) y ampliamente trabajado por la Universidad de Cornell en Nueva York. Esta universidad es la institución académica que más ha contribuido al conocimiento de sistemas OPR en restaurantes. La idea es determinar dos indicadores para cada plato: popularidad y contribución marginal. La popularidad es simplemente el porcentaje que cada plato tiene en las ventas totales y la contribución marginal es la diferencia entre el precio y el costo variable del plato. Un ejemplo de este cálculo se muestra en el cuadro 2.

$\begin{array}{lcccccccccc}\text { Opción } & \text { Cantidad } & \% \text { ventas } & \text { Popular } & \text { Precio } & \text { Costo } & \begin{array}{c}\text { Margen } \\ \text { contrib. }\end{array} & \begin{array}{c}\text { Total } \\ \text { ingreso }\end{array} & \begin{array}{c}\text { Total } \\ \text { costo }\end{array} & \begin{array}{c}\text { Total } \\ \text { margen }\end{array} & \text { Contrib. } \\ \text { Menú } 1 & 100 & 41 & \text { Alta } & 30,00 & 18,00 & 12,00 & 3.000,00 & 1.800,00 & 1.200,00 & \text { Baja } \\ \text { Menú } 2 & 50 & 20 & \text { Baja } & 45,00 & 25,00 & 20,00 & 2.250,00 & 1.250,00 & 1.000,00 & \text { Alta } \\ \text { Menú 3 } & 95 & 39 & \text { Alta } & 50,00 & 28,00 & 22,00 & 4.750,00 & 2.660,00 & 2.090,00 & \text { Alta } \\ & 245 & & & & & & & & 4.290,00 & \end{array}$

Cuadro 2. Ejemplo para el cálculo del Menu Engineering

En este caso se ha usado un umbral de $70 \%$ para la popularidad, esto es, todo plato que sobrepasa $0,7^{*} 100 / 3=23,33 \%$ es considerado de popularidad alta. En el caso de contribución, el punto de quiebre es el promedio ponderado, esto es, 4290/245 $=17,51$. Una vez que se tienen determinados los dos indicadores, estos pueden ser graficados en un plano dando lugar a los cuatro cuadrantes 
que se muestran en la figura 5. Por ejemplo, el Menú 1 tiene popularidad alta y contribución baja, quedando en el cuarto cuadrante. La recomendación es subir el precio o modificar el plato para mejorar la contribución. No es un plato para promociones. El Menú 2 tiene popularidad baja y contribución alta, quedando en el segundo cuadrante. Es un plato que puede promocionarse, soporta ofertas en precio y hasta podría renombrarse para intentar un nuevo lanzamiento buscando mayor popularidad. Por último, el Menú 3 tiene popularidad alta y contribución alta, quedando ubicado en el primer cuadrante. Es un plato estrella que puede promocionarse o no y que puede subir o bajar de precio, respondiendo siempre adecuadamente.

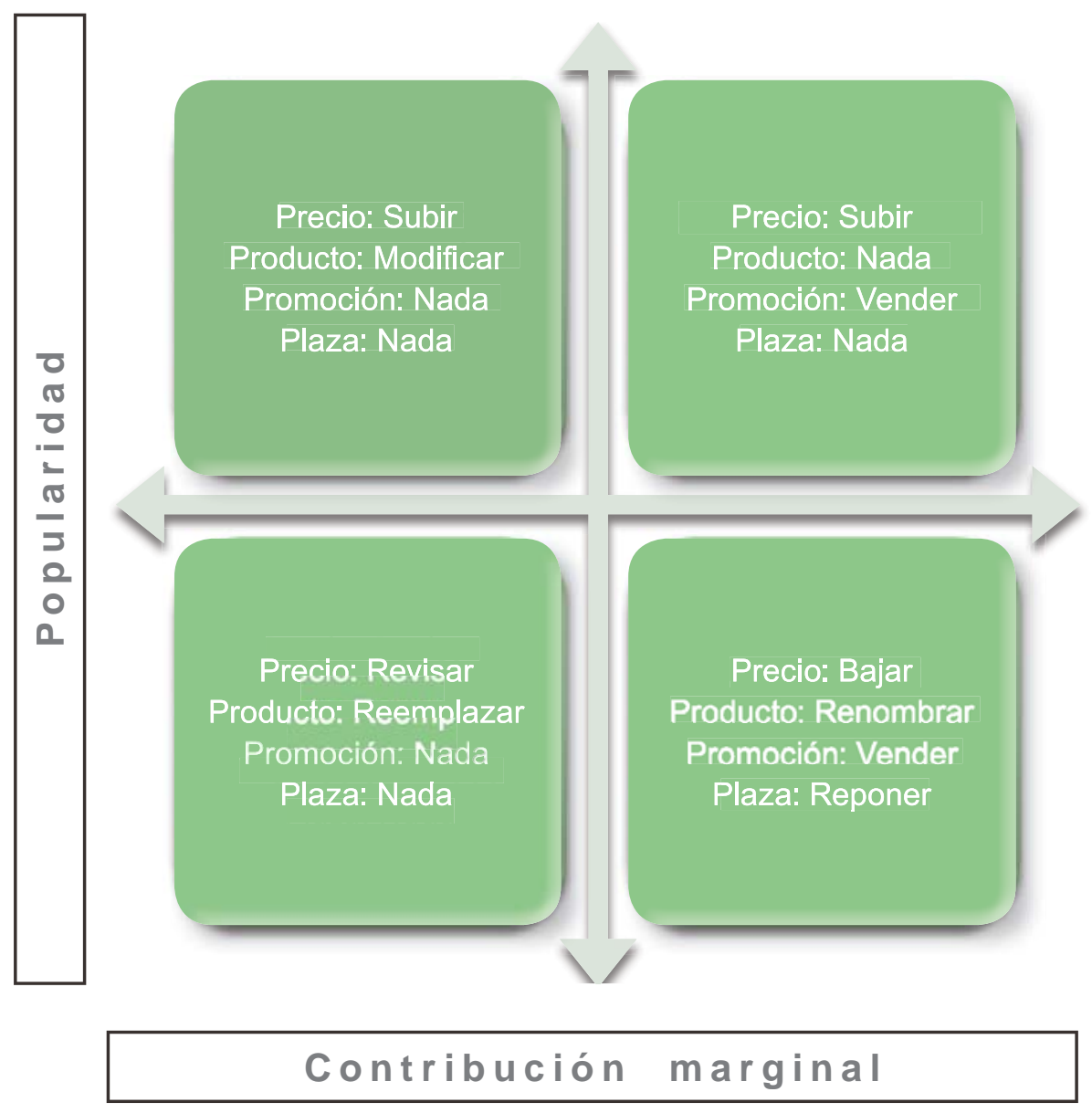

Figura 3. Cuadrantes para los resultados del Menu Engineering 
Las críticas a esta clasificación, simple pero valiosa, las encontramos en dos aspectos. El cálculo es ajeno a la incertidumbre de la demanda que se tendrá y se efectúa sobre la base de los resultados de las ventas anteriores y no sobre la base de los pronósticos de las ventas. Muchos restaurantes no hacen pronósticos y no queda más opción que calcular en base a las ventas anteriores. La propuesta consiste en efectuar los cálculos sobre pronósticos que incorporen la incertidumbre propia de toda demanda. La segunda crítica se refiere a que esta clasificación no provee ninguna información sobre cuál es el objetivo de ventas de las posibles promociones ni de cómo se debe orientar el uso de la capacidad del restaurante en la oferta de platos ya que no hay enlace alguno de los platos con la utilización de capacidad. En la literatura sobre el tema existen varios intentos de corregir estas limitaciones. LeBrutto (1997) propone la incorporación de un ranking sobre consumo de labor y Bell (2006) propone la inclusión de la técnica de costeo $A B C$ en lugar de la contribución marginal. En ambos casos las soluciones son parciales. Una nueva propuesta para corregir estas limitaciones es aplicar una lógica de optimización dinámica, utilizada generalmente en aplicaciones de Revenue Management de transporte y hotelería, la cual mostramos como ejemplo en la cuadro 3. Es un restaurante con seis platos cuyas ventas promedio semanales, precios y márgenes se muestran en la tabla adjunta. Igualmente, se muestran los cálculos ya explicados de popularidad (con un umbral de 100\%) y el margen de contribución.

\begin{tabular}{lcccccccc}
\multicolumn{1}{c}{ Platos } & $\begin{array}{c}\text { Vts prom } \\
\text { sem }\end{array}$ & Vts \% & Popularidad & Precio & Margen & Fact total & $\begin{array}{c}\text { Contr. } \\
\text { Marg.t. }\end{array}$ & $\begin{array}{c}\text { Nivel } \\
\text { contr. }\end{array}$ \\
Costillas & 600 & 27,27 & alta & 28 & 15,6 & 16.800 & 9.860 & alto \\
Fillet mignon & 500 & 27,73 & alta & 32 & 19,2 & 16.000 & 9.600 & alto \\
Brochetas de carne & 300 & 13,64 & baja & 26 & 19,1 & 7.800 & 5.730 & alto \\
Pollo primavera & 200 & 9,09 & baja & 24 & 5 & 4.800 & 1.000 & bajo \\
Pollo parmesiano & 400 & 18,18 & alta & 15 & 5,5 & 6.000 & 2.200 & bajo \\
Cordon bleu pollo & 200 & 9,09 & baja & 22 & 8 & 4.400 & 1.600 & bajo \\
\hline Total & 2.200 & 100 & 16,67 & & 13,40 & 55,800 & 29490 &
\end{tabular}

Cuadro 3. Ejemplo para la aplicación de la optimización del Menu Engineering

Se asume que el pronóstico de la futura demanda tiene una media igual a la venta promedio para cada plato pero una incertidumbre, que se muestra en la cuadro 4. Las demandas están aproximadas en cientos de platos y el valor de la celda es la probabilidad de que se dé dicha demanda. 


\begin{tabular}{|c|c|c|c|c|c|c|c|c|c|}
\hline \multicolumn{10}{|l|}{ Segmento: plato } \\
\hline & 0 & 1 & 2 & 3 & 4 & 5 & 6 & 7 & 8 \\
\hline Costillas & 0 & 0 & 0 & 0 & 0.1 & 0.2 & 0.4 & 0.2 & 0.1 \\
\hline Fillet mignon & 0 & 0 & 0 & 0.1 & 0.2 & 0.4 & 0.2 & 0.1 & 0 \\
\hline Brochetas de carne & 0 & 0.1 & 0.2 & 0.4 & 0.2 & 0.1 & 0 & 0 & 0 \\
\hline Pollo primavera & 0.1 & 0.2 & 0.4 & 0.2 & 0.1 & 0 & 0 & 0 & 0 \\
\hline Pollo parmesiano & 0 & 0 & 0.1 & 0.2 & 0.4 & 0.2 & 0.1 & 0 & 0 \\
\hline Cordon Bleu pollo & 0.1 & 0.2 & 0.4 & 0.2 & 0.1 & 0 & 0 & 0 & 0 \\
\hline
\end{tabular}

Cuadro 4. Pronóstico de la demanda en el ejemplo para la aplicación del Menu Engineering

Si se asume una capacidad máxima de 2.200 platos semanales se aplica un optimizador dinámico que maximice el margen de contribución total de los platos. El resultado numérico se muestra en la cuadro 5.

\begin{tabular}{|c|c|c|}
\hline Segmento & Decisión & Valor asociado \\
\hline 1 & 7 & 92,04 \\
\hline 2 & 6 & 94.08 \\
\hline 3 & 4 & 55,39 \\
\hline 4 & 0 & 0 \\
\hline 5 & 3 & 15,95 \\
\hline 6 & 2 & 12,8 \\
\hline 7 & 0 & 0 \\
\hline Total & 22 & 270,26 \\
\hline
\end{tabular}

Cuadro 5. Resultados de la optimización del Menu Engineering

Las conclusiones que se pueden obtener de esta optimización nos orientan sobre las decisiones que se deben tomar para las promociones, los cambios o las renovaciones de platos y objetivos de ventas. Los platos preferidos por el optimizador son los que tienen un buen margen, arriesgando su venta por encima de la demanda media (platos 1, 2 y 3). El plato 4, al tener poco margen y baja demanda, no se le considera y la recomendación es eliminarlo del menú. En conclusión, se sugiere promocionar los platos 1, 2 y 3, eliminar el plato 4 y dejar a su libre demanda los platos 5 y 6 . Luego de probar el optimizador en varios casos, 
asumiendo la existencia de ingredientes perecibles y no perecibles, se ha obtenido las siguientes conclusiones:

- Si se tienen platos cuyos ingredientes no se pueden almacenar (perecibles) y se pierden si no se venden, se recomienda tratar de no arriesgar en ellos; esto es, no planear ventas por encima de sus promedios. Si el costo variable es muy alto se sugiere planear cantidades inferiores a las ventas promedios para disminuir el riesgo.

- Si se tienen platos cuyos ingredientes se pueden almacenar si no se vendieran (no perecibles), se puede arriesgar en la promoción de los platos que más contribuyen con el margen y estar listos para recibir una demanda mayor que las ventas promedios. Herramientas como las sugerencias de chef, degustación de platos recomendados, fotos especiales en las listas, ubicación y resalte en las listas, etcétera, son adecuadas para promocionar los platos. Además, se deben eliminar los platos que tienen poco margen para dar espacio a las promociones de los que tienen mayores márgenes.

- Los platos con indicadores bajos tanto en popularidad como en contribución marginal son los que normalmente deben ser eliminados o cambiados de manera radical. En el ejemplo se tiene el caso del plato 4 (Pollo primavera). En el caso del plato 6 (Cordon Bleu pollo), que también está en esa situación, el optimizador no llega a recomendar su eliminación ya que su margen no es tan bajo. El optimizador está calculando con exactitud las contribuciones mientras que el indicador es solo una referencia general.

\section{Gestión de operaciones}

La determinación de cuál de los recursos de un restaurante es el que limita su capacidad y de cómo la cantidad de cualquiera de los recursos y la manera de actuar de estos afectan dicha capacidad constituyen el tema de gestión de operaciones. Una herramienta de este tipo permite obtener los datos requeridos por la gestión de rentabilidad y la ingeniería del menú, además de servir como medio para mejorar la eficiencia, la productividad y las ventas del restaurante. La técnica a usar es la simulación, con muchos antecedentes exitosos en el área de restaurantes. El impacto de modelos de simulación en restaurantes ha producido millones de dólares en ahorros o en utilidades tanto en el diseño como en la operación de muchos casos reportados (Brann y Kulick 2002).

El objetivo de la simulación efectuada es permitir un ambiente en el cual se pueda evaluar el efecto de las acciones tácticas como consecuencia de la medición del RevPash y de la ingeniería del menú en la rentabilidad del restaurante. Se ha tratado de dar la mayor flexibilidad en el modelo para que puedan ser configurados 
distintos tipos de restaurantes. Las características y potencialidades del modelo de simulación, formulado en Arena, se van describiendo en la presentación de los resultados.

Características del modelo orientadas al objetivo:

- Considera los siguientes recursos y permite alterar sus capacidades:

- anfitrionas,

- mozos,

- cocineros,

- mesas,

- cajeros, y

- ayudantes de limpieza.

- Permite relacionar el precio (o promoción) de los platos con la demanda correspondiente por horas y por días de atención.

- Considera la posibilidad de pérdida de clientes en función del tamaño de la cola de espera para la asignación de mesa en el restaurante.

- Permite la relación entre el tiempo que dedican los mozos a un cliente con los pedidos adicionales durante el consumo.

- Genera todos los datos necesarios para medir el RevPash, la contribución semanal total, la duración del servicio, el tiempo de espera para recibir la asignación de mesa, la ocupación de sillas y los clientes perdidos por colas de espera excesivas.

Experimento

- El modelo de simulación se aplica sin ninguna acción táctica definida con la intención de capturar datos para determinar el mapeo de RevPash por una semana.

- Se calcula el mapeo de RevPash para lapsos de media hora.

- Se determinan las acciones tácticas adecuadas a la medición obtenida y se incorporan al modelo.

- Se corre el modelo con las acciones incorporadas y se vuelve a determinar el mapeo de RevPash.

- Se repite el experimento para diversas afluencias de clientes al restaurante (demandas baja, media, alta y muy alta).

- Se prueba el efecto estadístico de las acciones tácticas en los indicadores mediante 30 replicaciones (semanas). 


\section{Análisis de resultados}

Los resultados serán ordenados según los cuatro escenarios de demanda:

- Demanda baja (muy por debajo de la capacidad)

- Demanda media (moderadamente debajo de la capacidad)

- Demanda alta (alrededor de la capacidad)

- Demanda muy alta (claramente por encima de la capacidad)

En cada uno de ellos se efectuará el experimento descrito mostrándose y analizándose los resultados obtenidos.

\section{Demanda baja}

Lo primero que se hace es correr el simulador por una semana en la que el restaurante está sometido a una demanda muy por debajo de su capacidad y funcionando sin ninguna acción especial. Se obtienen todos los valores requeridos para el cálculo del RevPash, el cual se muestra en la tabla 1. Se nota claramente un RevPash con valores bajos que se evidenciarán cuando se observen los cálculos de los otros escenarios. Al buscar zonas de comportamiento específico se observan algunas con valores especialmente bajos que pueden agruparse en las siguientes:

- Días completos: martes, miércoles y jueves

- Horas adicionales: de 11 a 13:30 los viernes, sábados y domingos.

Como conclusión se deben tomar acciones generales (para toda la operación) y acciones específicas (por días y por horas). Las acciones generales que se tomarán son:

- Promoción de grupos de afinidad (tarjetas habientes, clientes frecuentes, etcétera) que generan un descuento general promedio del $10 \%$ y un aumento de demanda del $20 \%$.

- Promoción de bebidas y postres por los mozos originando un aumento de la probabilidad de ordenar de 50\% a 80\%, pero duplicando el tiempo consumido por los mozos.

La acción específica que se tomará será un descuento del 20\% que originará un aumento de demanda de un $40 \%$ en los siguientes horarios:

- Todo el día los martes, miércoles y jueves (happy days).

- De 11 a 13:30 los días viernes, sábados y domingos (happy hours). 
Estas acciones son incorporadas al simulador y se vuelven a medir los RevPash. La tabla 2 muestra los resultados. La mejora es considerable subiendo de una contribución total semanal de S/.9.795 a S/.16.300. Además, se nota un RevPash más uniforme durante la semana. Queda la duda del día viernes, que pudo pasar al descuento total pero no se trata de lograr la mayor contribución posible sino de demostrar que el uso de lógicas alineadas al RevPash da resultados claramente superiores en rentabilidad.

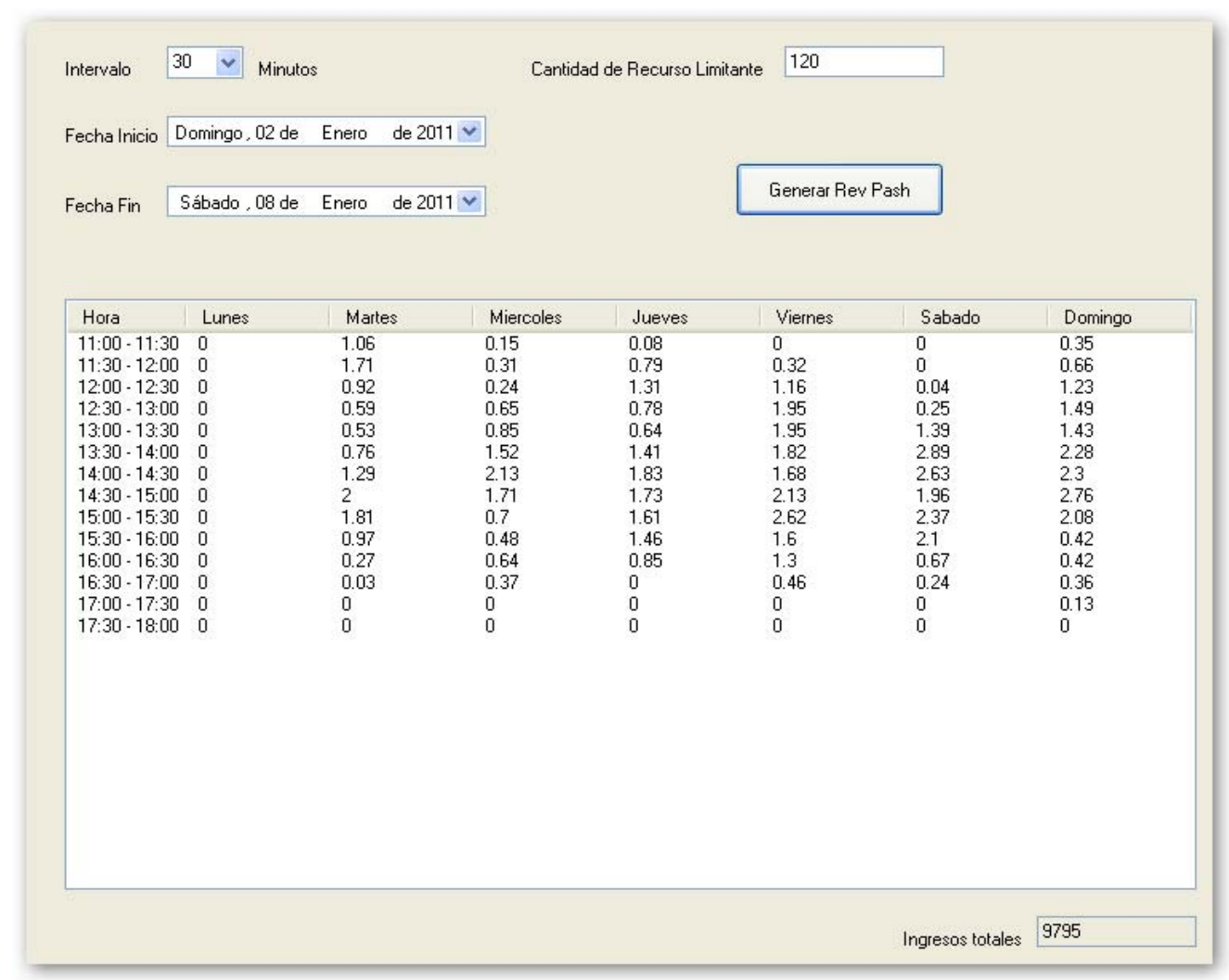

Tabla 1. RevPash escenario original, demanda baja

Al efectuarse una comparación con validez estadística para cada uno de los indicadores de operación explicados se encuentran los siguientes resultados. En la tabla 3 se pueden ver los intervalos de confianza de 95\% para el indicador de contribución semanal. Se concluye que existe un aumento estadísticamente significativo de aproximadamente $\mathbf{S} .5 .400$ al usar las acciones recomendadas por el RevPash. Los resultados para la demora promedio del servicio en minutos se muestran en la tabla 4, observándose un aumento estadísticamente significativo de aproximadamente cuatro minutos. 


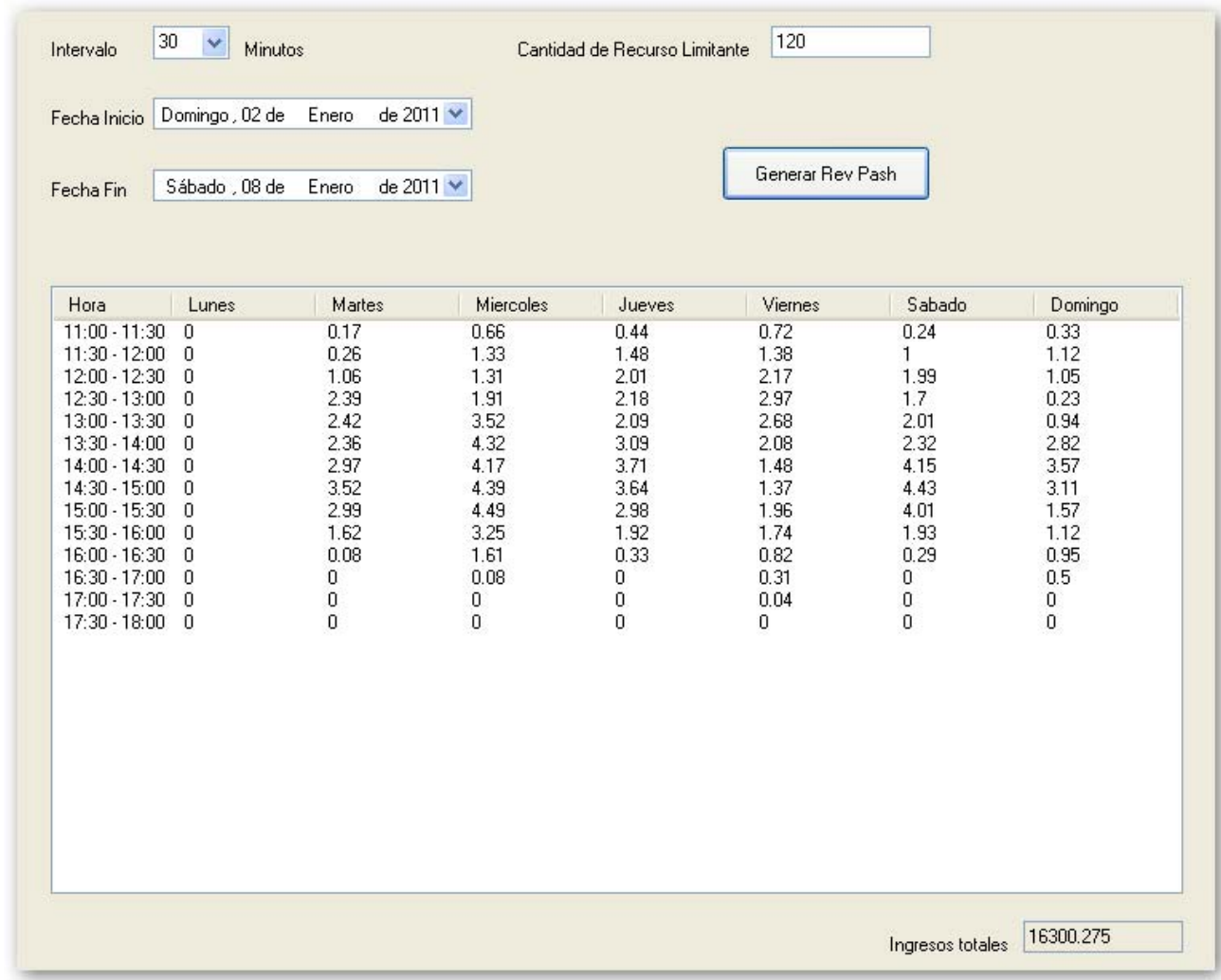

Tabla 2. RevPash escenario RM, demanda baja

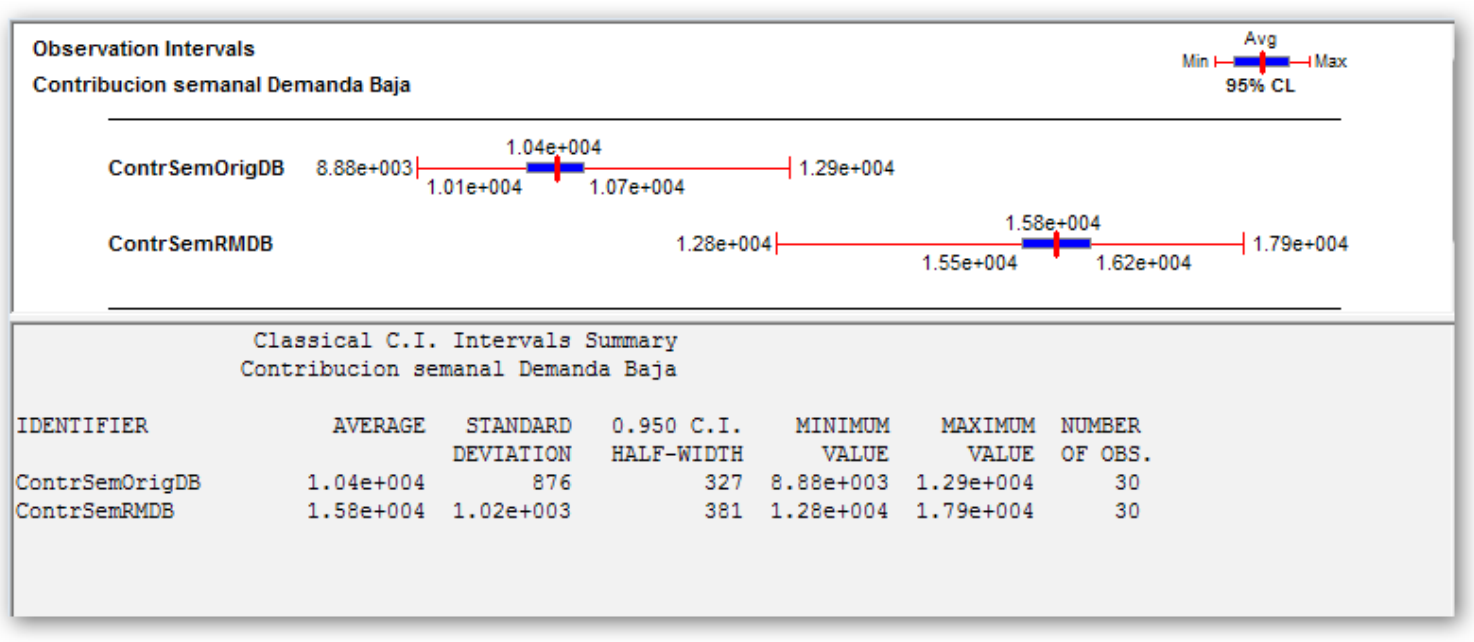

Tabla 3. Intervalos de confianza, escenario demanda baja, indicador contribución semanal 


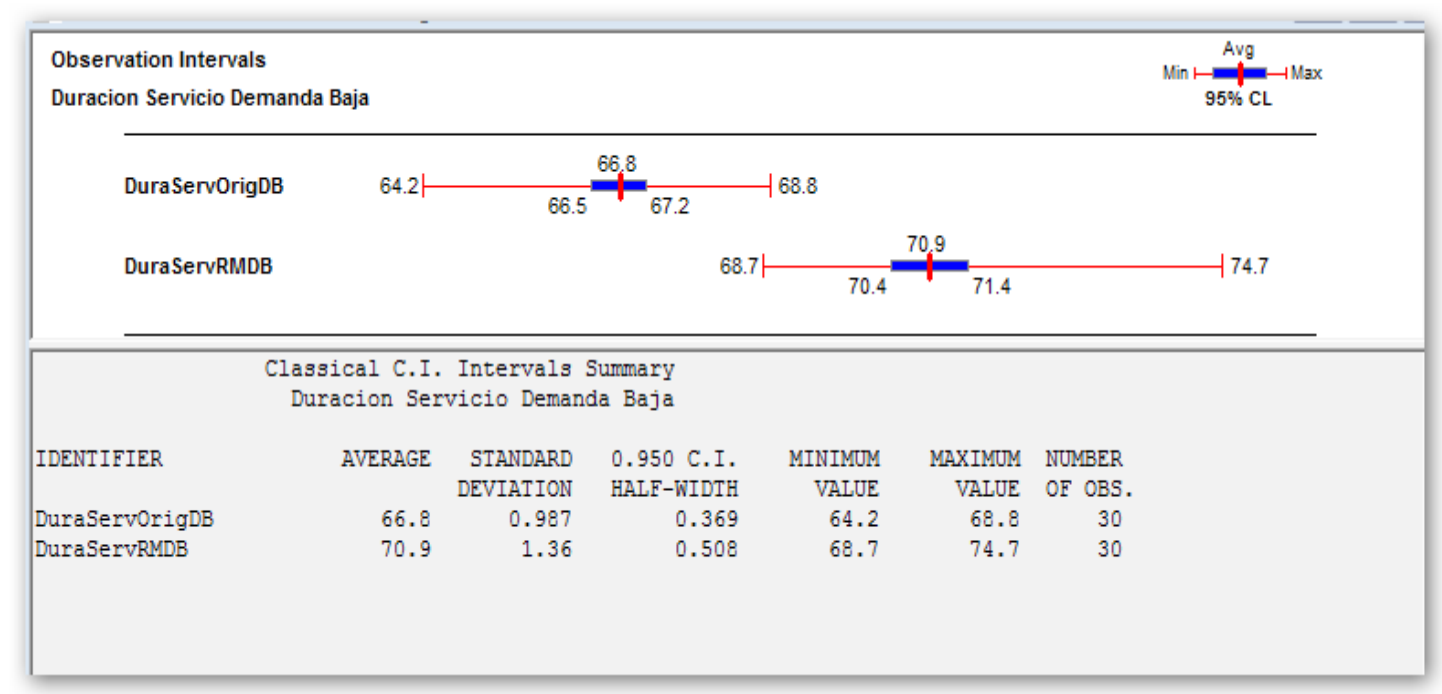

Tabla 4: Intervalos de confianza, escenario demanda baja, indicador duración de servicio

\section{Demanda media}

Los resultados del RevPash en este escenario sin acciones de ningún tipo se pueden ver en la tabla 5. Encontramos una mejor posición del indicador con respecto al escenario anterior recomendando una sola acción general, la referida a la promoción de bebidas y postres por los mozos originando un aumento de la probabilidad de ordenar de 50\% a 80\%, pero duplicando el tiempo consumido por los mozos. Para acciones específicas, si se observan dos zonas de bajo RevPash se recomienda un descuento del 20\% que originará un aumento de demanda de un 40\% en los siguientes horarios:

- Todo el día los jueves (happy day).

- De 11 a 13:30 en todos los otros días (happy hours). 


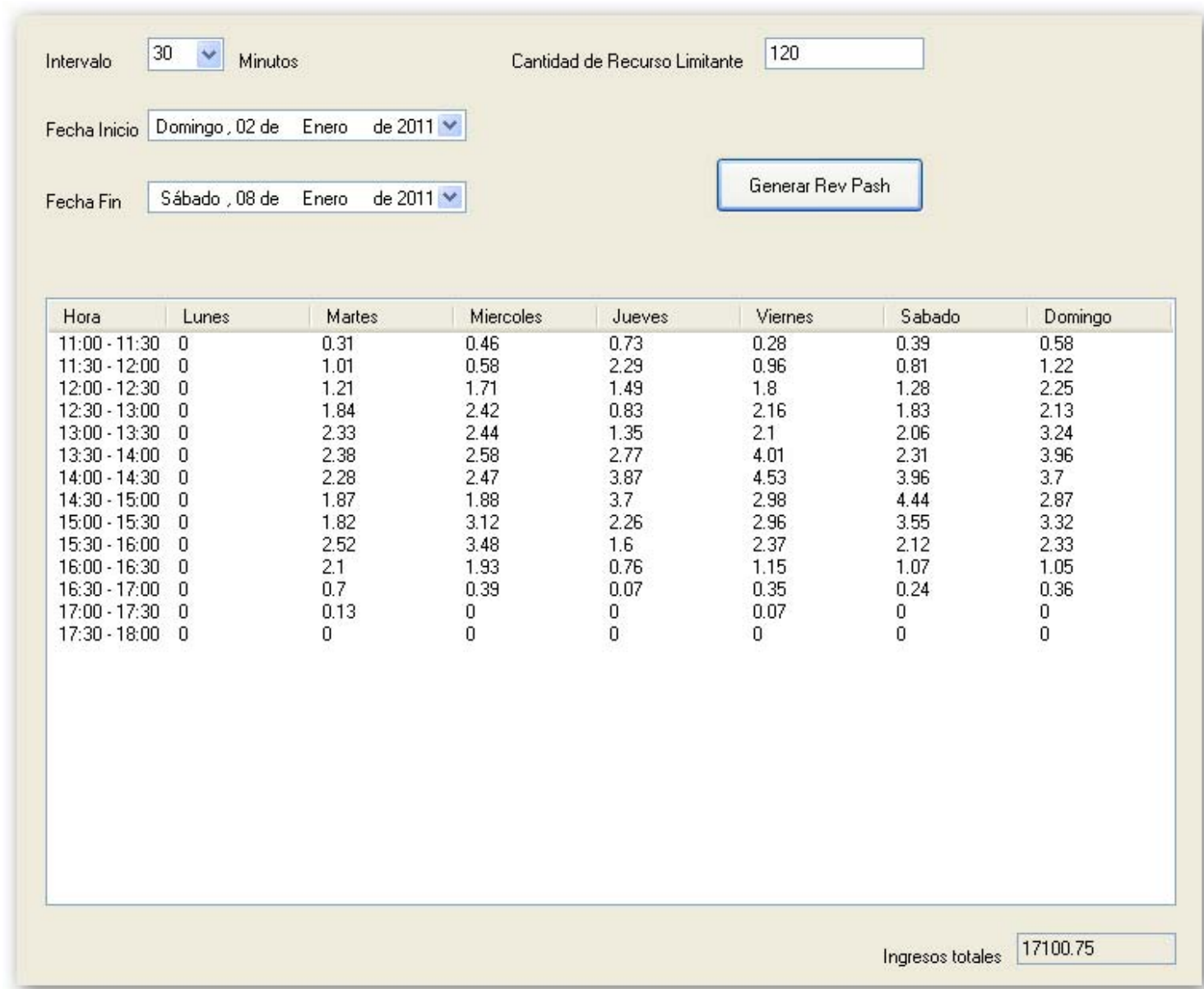

Tabla 5: RevPash escenario original, demanda media

Al aplicar estas acciones al simulador se vuelven a generar los RevPash y se obtienen los resultados mostrados en la tabla 6. La contribución semanal total subió de S/.17.100 a S/.23.983 y los valores del indicador se ven más homogéneos. 


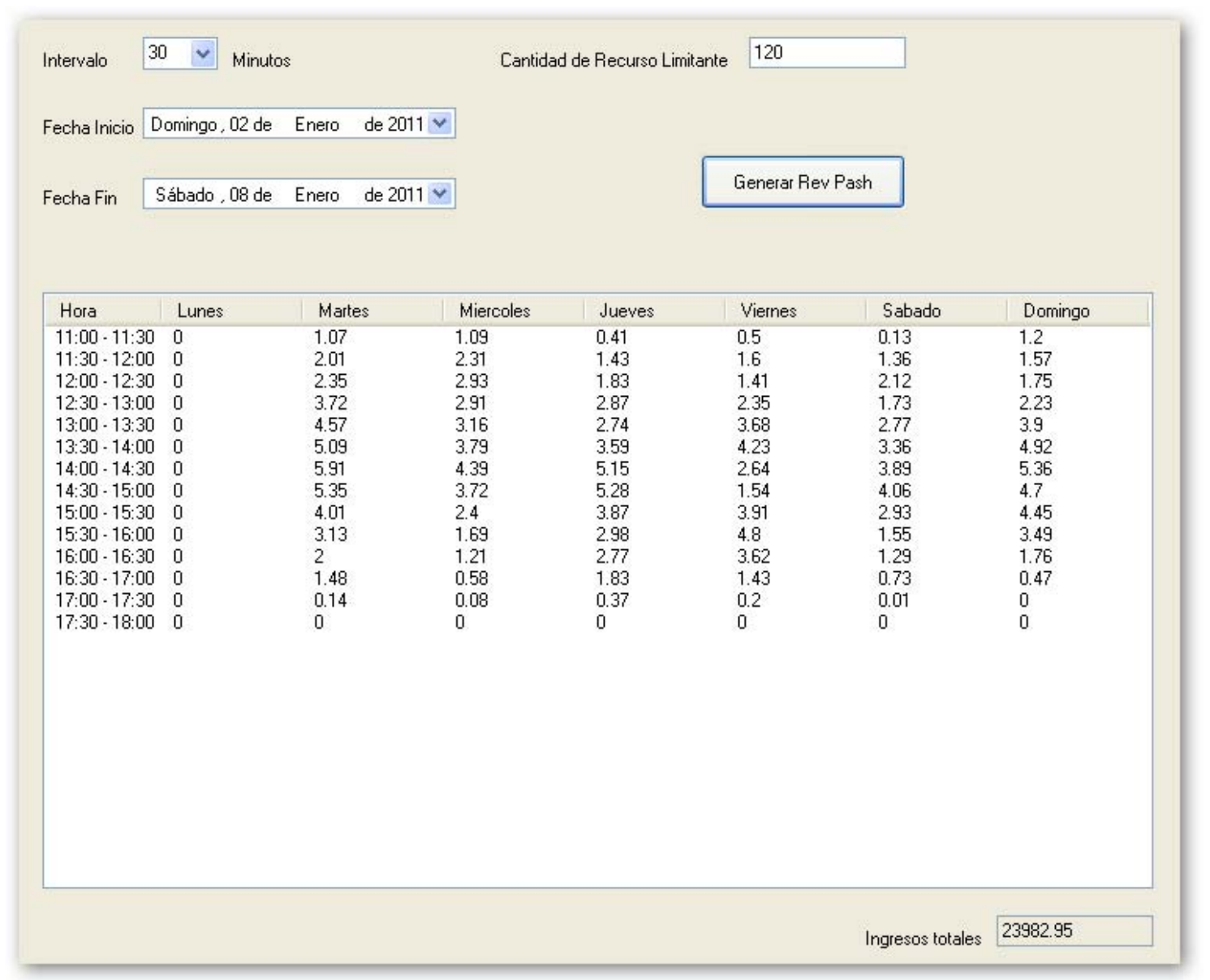

Tabla 6: RevPash escenario RM, demanda media

Se efectúan los experimentos estadísticos para los dos indicadores mostrándose los resultados en las tablas 7 y 8 . En todos ellos se observa un aumento estadísticamente significativo. En la contribución semanal el aumento es de aproximadamente S/. 6.900 y en la duración del servicio es de aproximadamente 5,7 minutos. 


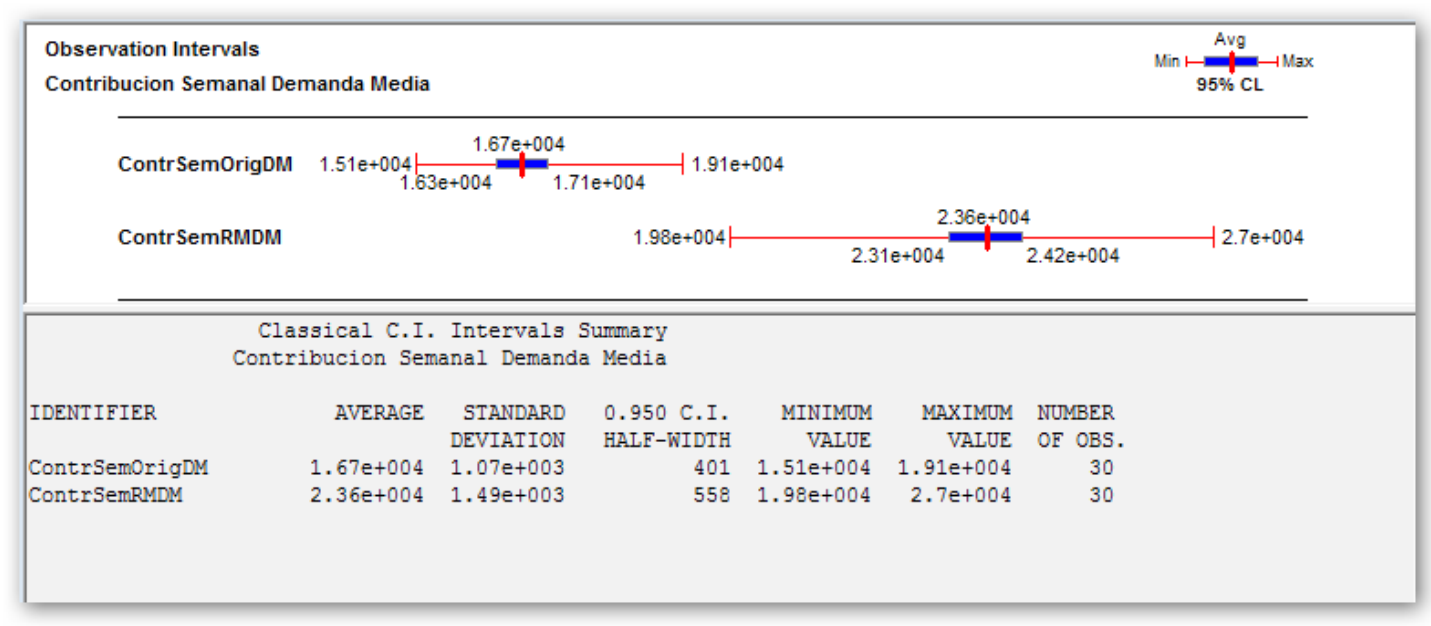

Tabla 7. Intervalos de confianza, escenario demanda media, indicador contribución semanal

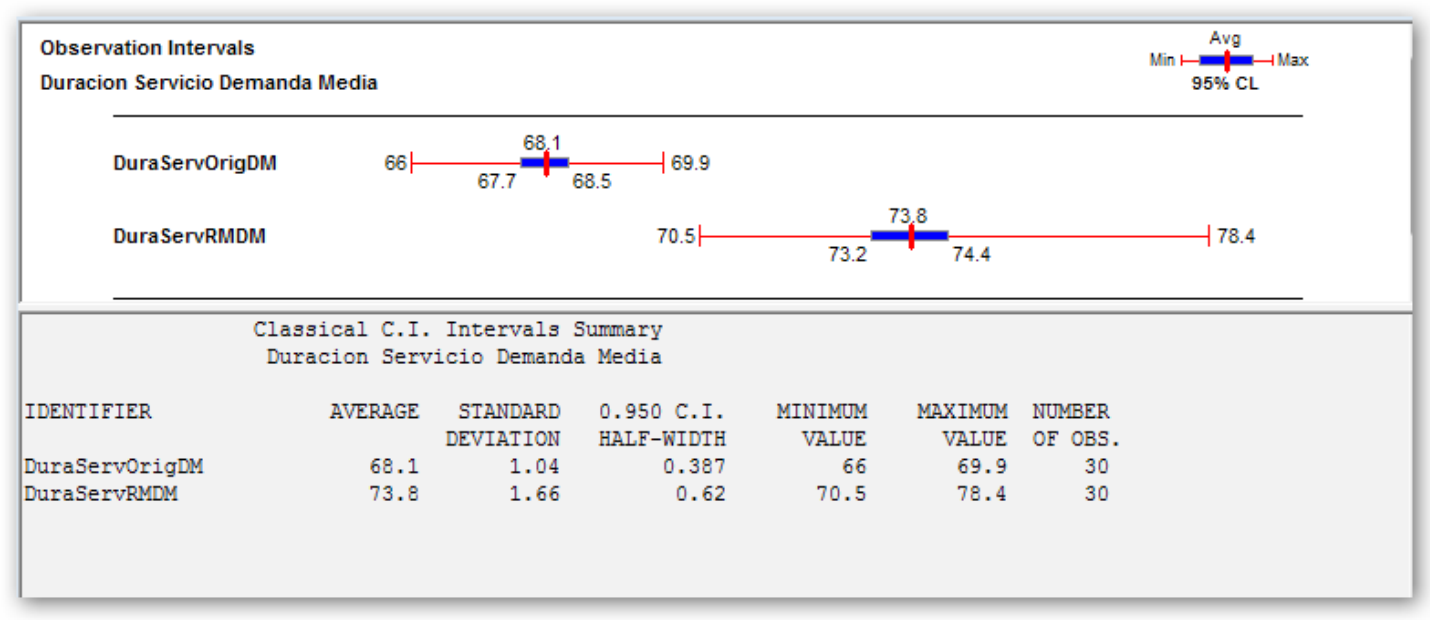

Tabla 8. Intervalos de confianza, escenario demanda media, indicador duración de servicio 


\section{Demanda alta}

En este escenario las acciones a tomar deben ser más focalizadas, ya que la demanda está mucho más acorde con la capacidad del restaurante. Si se observan los resultados de los RevPash en la tabla 9 se ven valores mayores pero falta homogeneizarlos por el lógico efecto de las variaciones de demanda por días y por horas. Con estos resultados solo se recomiendan las siguientes acciones específicas:

- Promoción de bebidas y postres por los mozos, que origina un aumento de la probabilidad de ordenar de $50 \%$ a $80 \%$ pero duplica el tiempo consumido por los mozos. Esta promoción se aplica todo el día los martes, miércoles y jueves. En los días viernes, sábado y domingo solo se aplica de 11:00 a 13:00 horas.

- Descuento del 20\%, que originará un aumento de demanda de un $40 \%$ en el horario de 11 a 13 todos los días (happy hours).

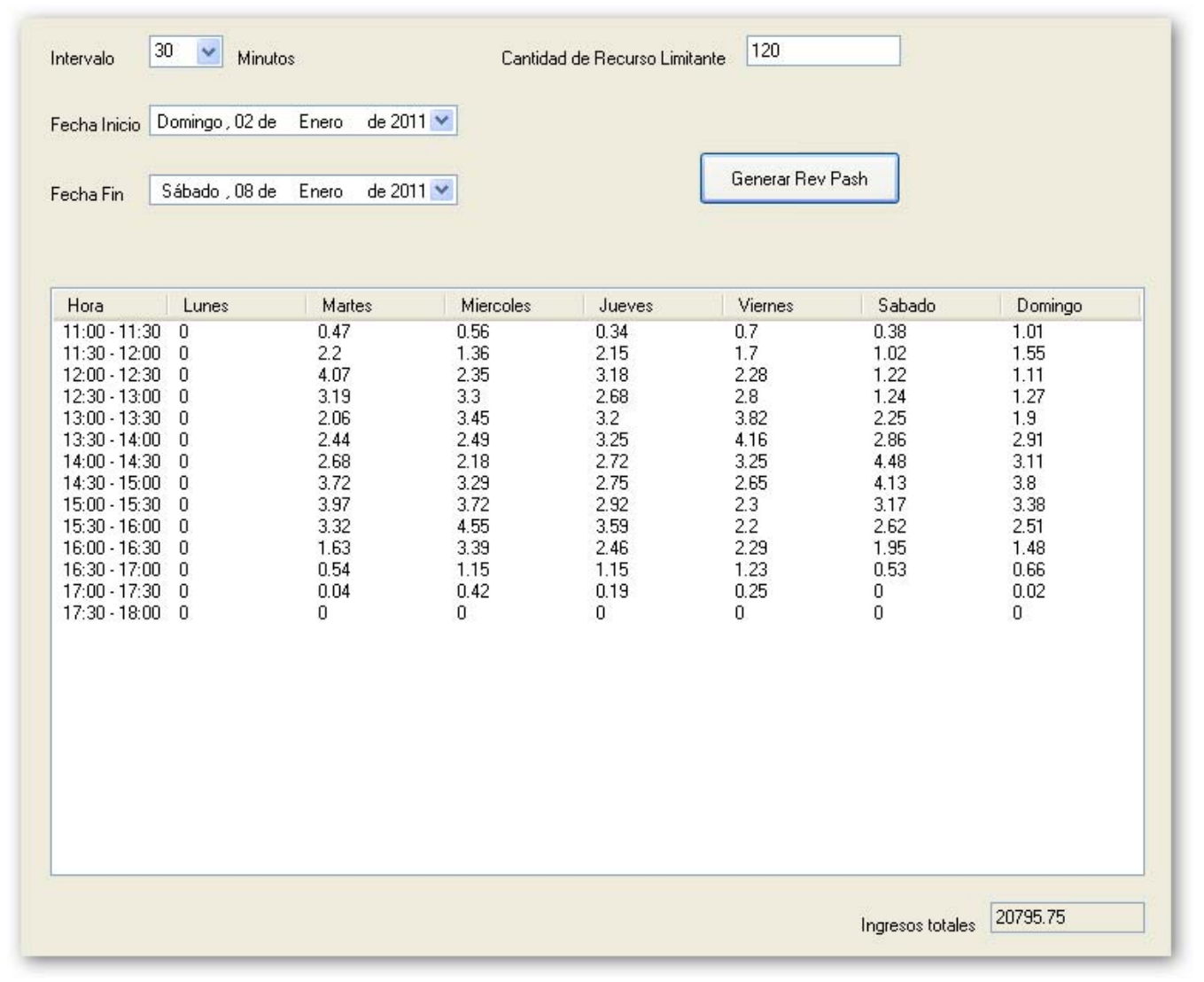

Tabla 9. RevPash escenario original, demanda alta 
Los nuevos resultados del RevPash al aplicar estas acciones se muestran en la tabla 10. La mejora es considerable, pasando de una contribución marginal de S/.20.796 a una de S/.29.932. La homogeneización de los valores se nota claramente.

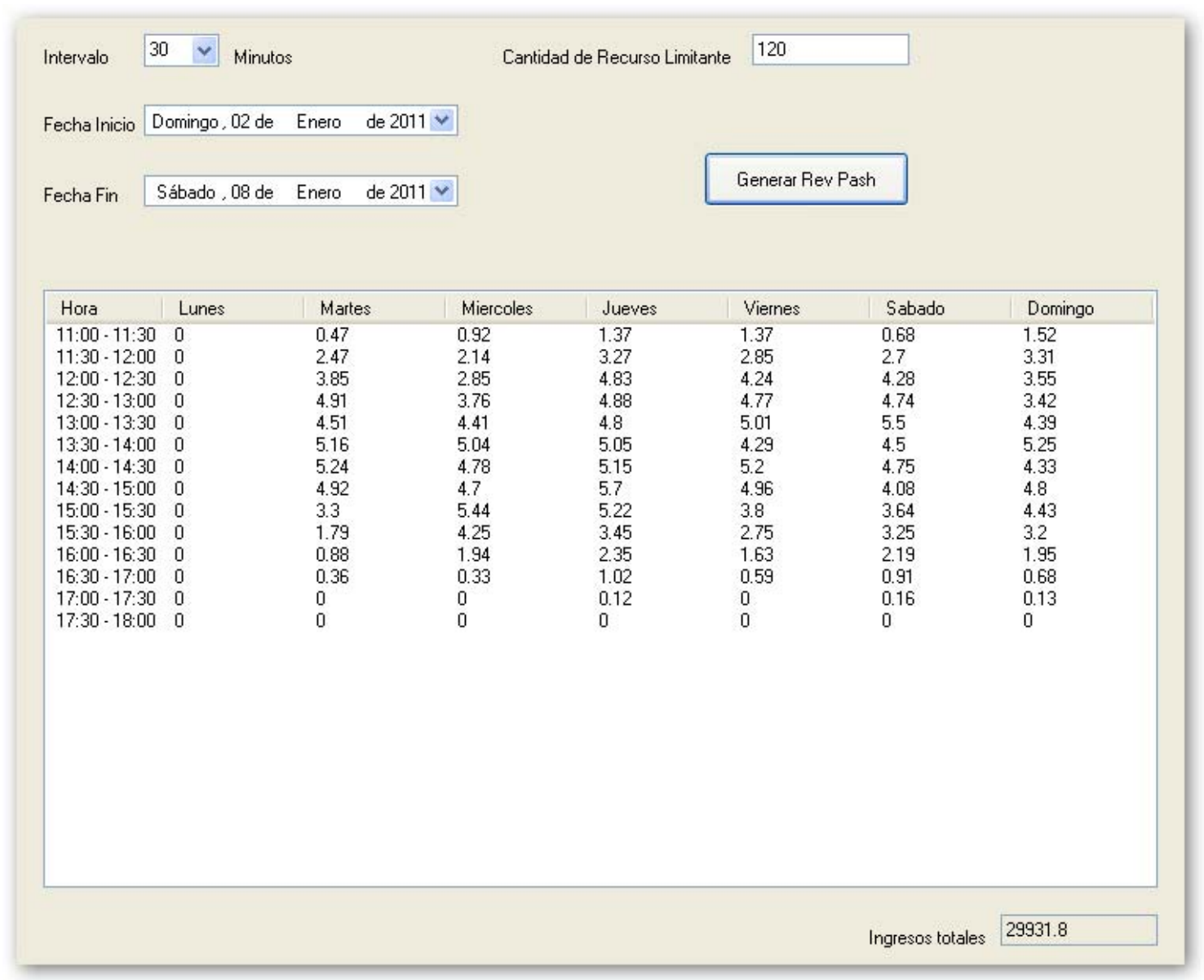

Tabla 10. RevPash escenario RM, demanda alta

Al igual que en el escenario anterior, en el análisis estadístico los dos indicadores muestran aumentos significativos, los cuales se presentan en las tablas 11 y 12. La contribución semanal tiene un aumento aproximado de S/. 6.600 y la duración de servicio es de 7,2 minutos. 


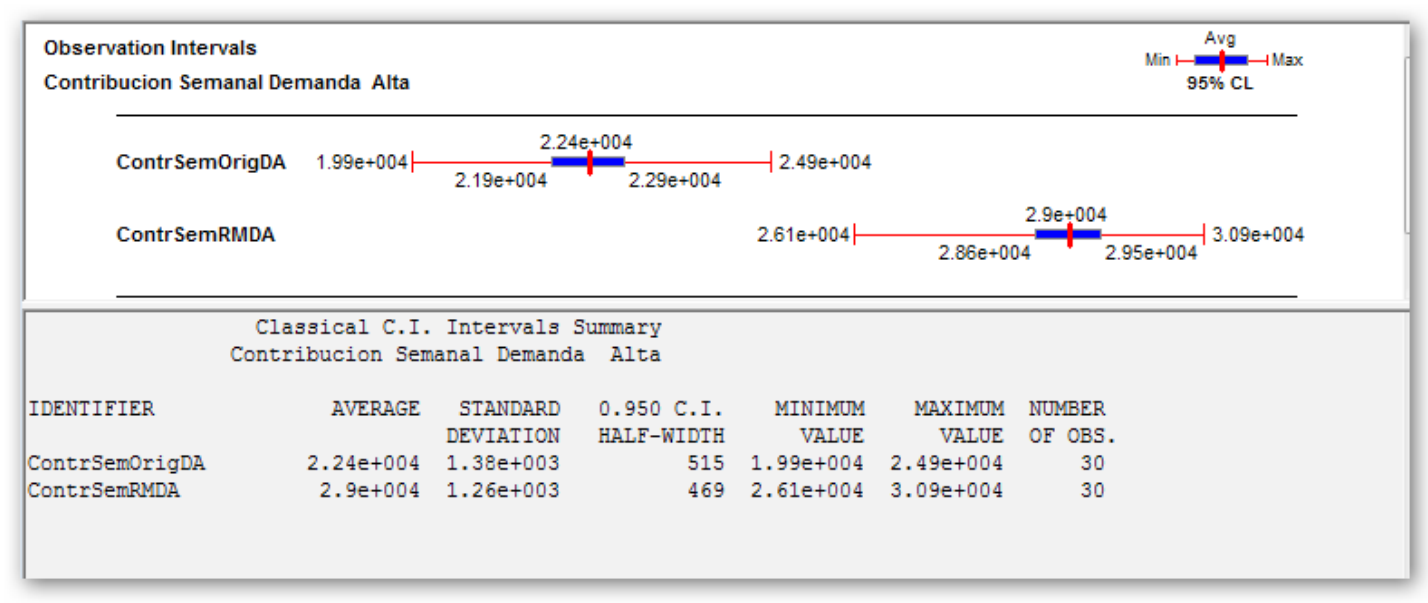

Tabla 11. Intervalos de confianza, escenario demanda alta, indicador contribución semanal

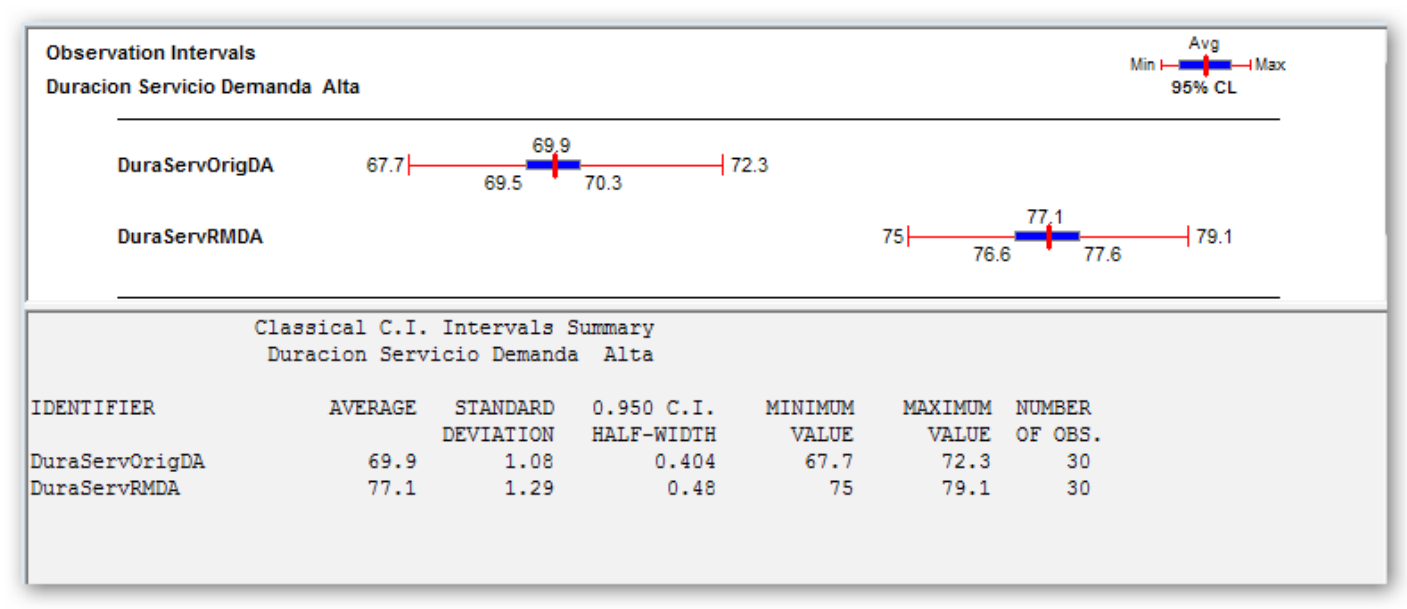

Tabla 12: Intervalos de confianza, escenario demanda alta, indicador duración de servicio

\section{Demanda muy alta}

Este escenario es completamente distinto a los anteriores. En este caso se está frente a una demanda que supera la capacidad de atención del restaurante. El objetivo para el análisis del RevPash es, sin ninguna duda, aumentar su valor, pero con acciones totalmente distintas. Ya no se trata de atraer más clientes sino que la duración de la atención se pueda hacer más rápida pero sin afectar la sensación de 
comodidad del cliente. En la tabla 13 se observa el mapeo de RevPash conseguido sin acción alguna. Todavía se aprecian zonas frías en el inicio diario de las operaciones pero en general se alcanza un valor alto en el resto de las horas. La recomendación va en dos sentidos: Por un lado, aumentar los recursos humanos del restaurante en las horas pico (dos mozos, una anfitriona, un cajero y un limpiador), y por otro lado, seguir con el descuento del happy hour pero solo de 11:00 a 12:00 horas, todos los días.

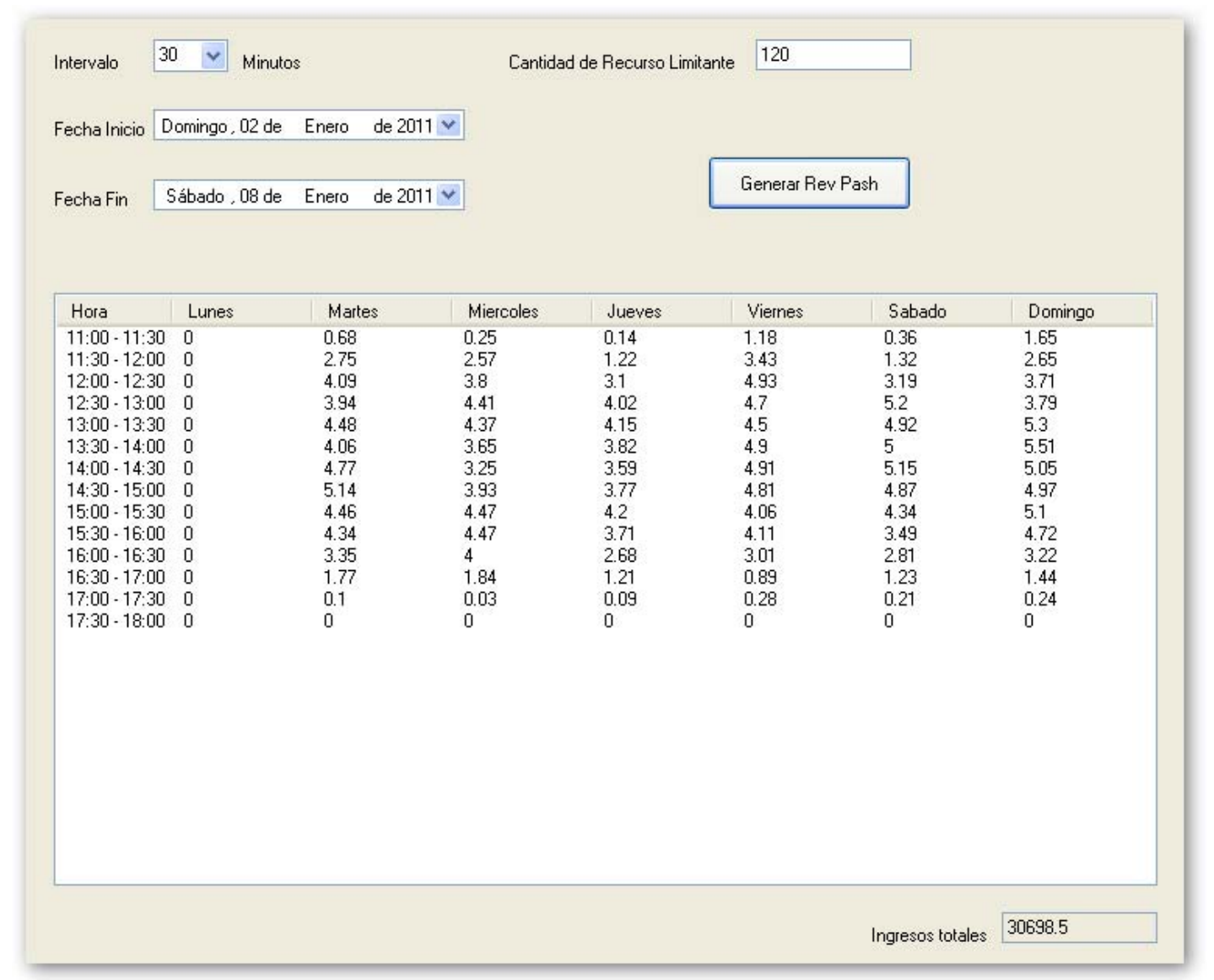

Tabla 13. RevPash escenario original, demanda muy alta

El resultado obtenido en el RevPash después de estas acciones se observa en la tabla 14. La contribución semanal sube de S/.30.698 a S/.35.336. Además de ser un aumento menor que en los escenarios anteriores, en este caso se debe medir su verdadero beneficio luego de descontar el gasto que originen los mayores recursos. 


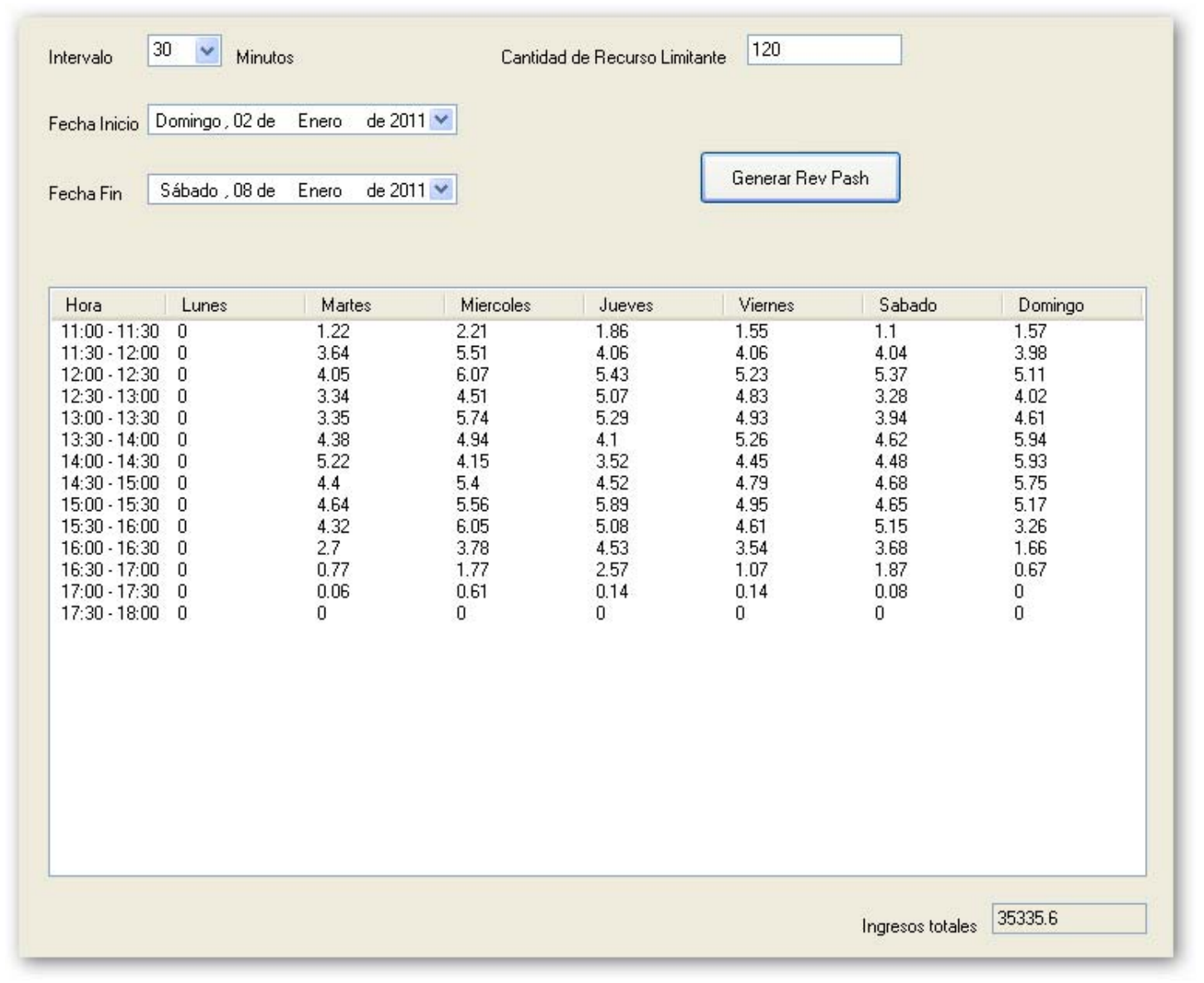

Tabla 14. RevPash escenario RM, demanda muy alta

Al pasar a las comparaciones estadísticas de los cuatro indicadores también se encuentran resultados completamente distintos, tal como se muestran en las tablas 15 y 16 . La contribución semanal aumenta con significancia estadística aproximadamente $\mathrm{S} / .3 .000$, pero la duración del servicio disminuye en aproximadamente 5,8 minutos, tal como fue el objetivo. 


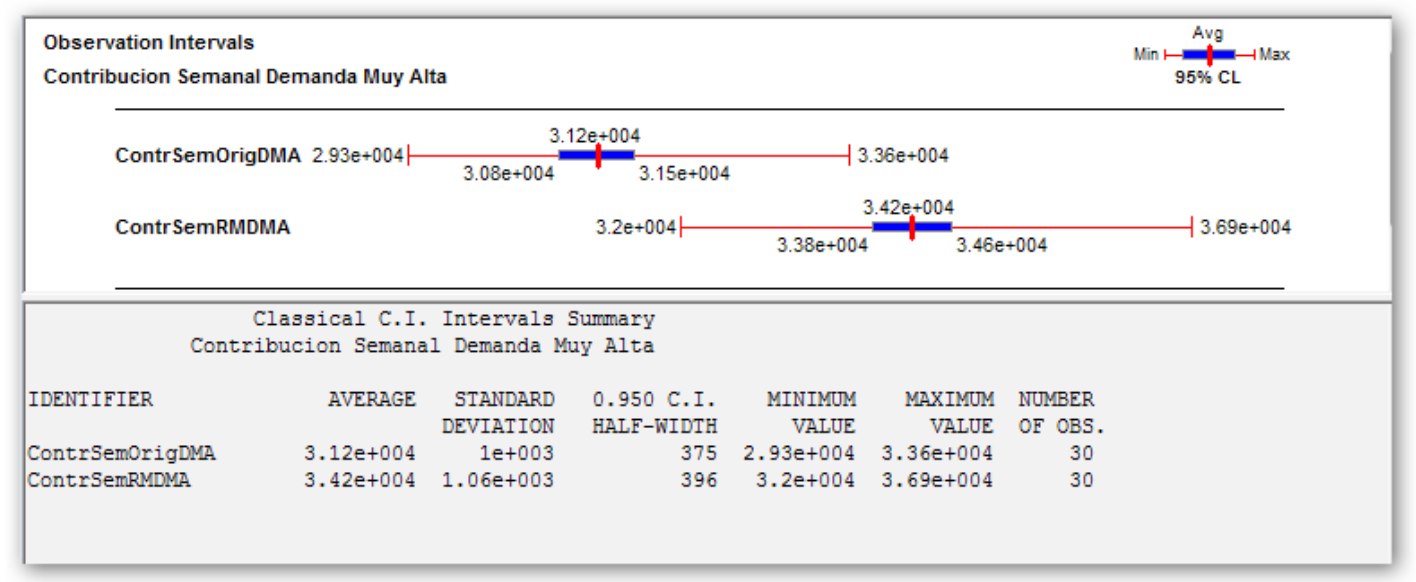

Tabla 15. Intervalos de confianza, escenario demanda muy alta, indicador contribución semanal

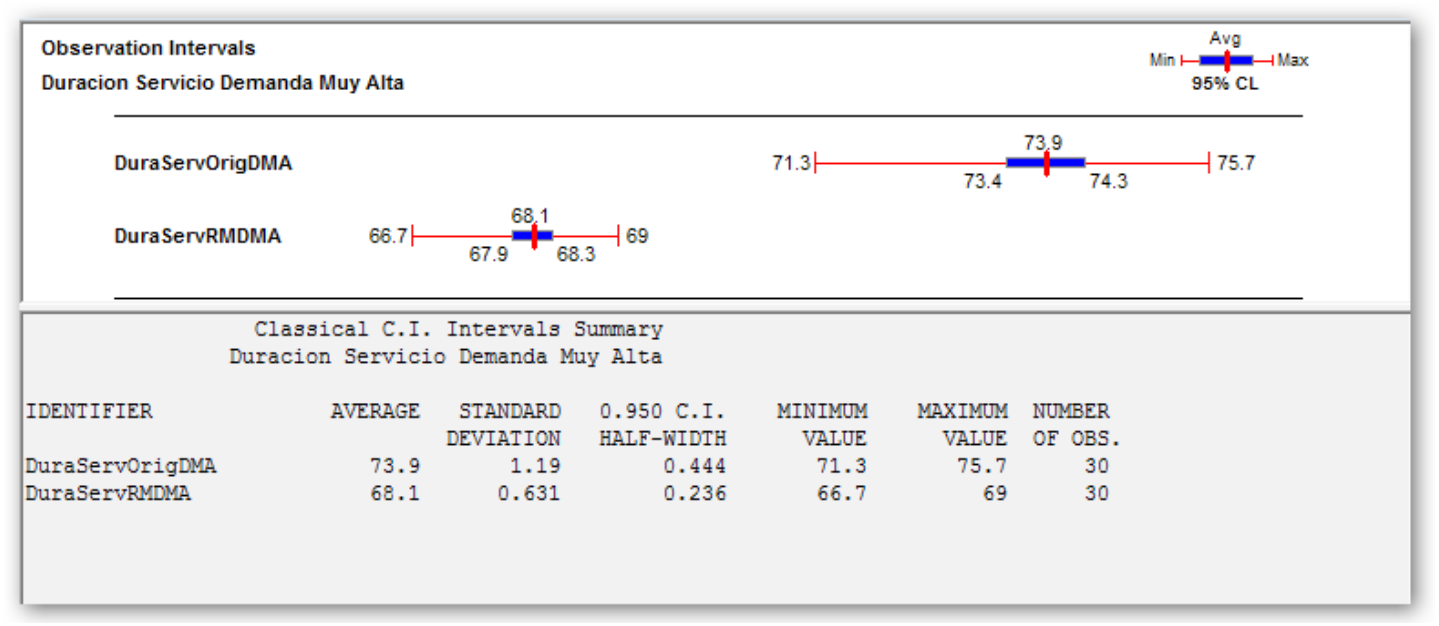

Tabla 16. Intervalos de confianza, escenario demanda muy alta, indicador duración de servicio

\section{Conclusiones}

La aplicación de los sistemas de optimización de precios y rentabilidad (Pricing \& Revenue Management) en restaurantes ha venido siendo discutida por varios investigadores en más de una institución (Thompson y Sohn 2008, Kimes 2008). Los beneficios y la forma de aplicarlos no han quedado del todo claros. El objetivo de este trabajo de investigación ha sido justamente demostrar cómo determinadas formas simples de aplicar estas herramientas tácticas pueden llevar a obtener 
beneficios significativos en cualquier nivel de demanda del restaurante. El pensamiento que subyace tras estos sistemas es que si una operación cuenta con capacidad relativamente fija, con inventario perecible (si una silla de un restaurante no es ocupada en una determinada hora, la posibilidad de generar dinero por ese recurso perece), con demanda variable en el tiempo y con un mercado que se puede segmentar; es posible comprender la percepción del valor del producto que los clientes tienen para así alinear el precio, el lugar y la disponibilidad con los distintos segmentos de mercado que una empresa atiende (Gross et al. 2011). Esa segmentación no ha sido comprendida por muchos administradores de restaurantes. Entre los clientes hay tres tipos de segmentos: a) los muy sensibles a los precios, que prefieren momentos de baja demanda con tal de conseguir precios que estén de acuerdo con su valoración; b) los poco sensibles a los precios, quienes están dispuestos a pagar más con tal de que el servicio sea a la hora elegida por ellos; y c) los que requieren atenciones especiales para decidir su consumo. Los sistemas OPR en restaurantes son la oportunidad de conseguir estas alineaciones.

El indicador apropiado para soportar estos sistemas es el RevPash, el cual mide el flujo de ingreso (como contribución marginal) por unidad de espacio-tiempo. Para conseguir mediciones que permitan efectuar experimentos que demuestren el beneficio de los sistemas OPR se ha construido un simulador de restaurantes sobre la base de realidades observadas. El simulador es suficientemente flexible, pudiendo fácilmente adecuarse a cualquier realidad. Se ajustaron los parámetros de la operación del restaurante simulado para que refleje las expectativas observadas de duraciones de servicio encontradas en la literatura de la especialidad (Kimes 2008). La media esperada es de una hora, con variaciones menores hacia arriba y hacia abajo. Las acciones tácticas usadas para mejorar el RevPash se encuentran en dos grandes grupos. Las que aumentan la demanda del restaurante, ya sea por descuentos de precio (happy days o happy hours) o por promociones internas (postres y bebidas), y las que disminuyen la duración del servicio por aumento de recursos o por dejar de promocionar mayores consumos. Todas estas tácticas se usaron en cuatro escenarios de distinta demanda, consiguiéndose beneficios significativos en todos ellos en función de dos indicadores contribución marginal y duración del servicio.

Se está frente a una mejora en servicio y en rentabilidad de restaurantes tanto para propietarios como para clientes. Los primeros recibirán mayor contribución por sus inversiones y los segundos un servicio adecuado y con el valor que ellos perciben. No queda más que recomendar la mayor difusión de estos conceptos. 


\section{Extensiones}

Efectuado todo el experimento de esta investigación encontramos varios aspectos en que puede ser ampliada para seguir contribuyendo con el tema de sistemas OPR en restaurantes, entre ellos los que se encuentran los siguientes:

- Normalmente, los restaurantes trabajan sobre reglas FIFO para el ingreso de los clientes conforme van llegando. En este estudio se observó la cantidad máxima de sillas ocupadas por el restaurante tomando en cuenta que solo tiene mesas de cuatro sillas. Los resultados obtenidos indican que aun con lista de espera de clientes, la cantidad de sillas ocupadas no llega al máximo esperado. Lo que sucede es que los tamaños de los grupos no coinciden con la distribución de sillas y las mesas. Ante ello surge la posibilidad de que el manejo de la espera o de la reserva en los casos que el restaurante acepte, sea efectuada en conveniencia de consumo para el restaurante. En nuestro caso simple, un grupo de cuatro es mucho más rentable que un grupo de cinco o seis al calcularlo por persona cuando las mesas están ocupadas. El simulador construido puede ser fácilmente utilizado para una investigación de este tipo.

- Ante la situación anterior, el restaurante podría cuestionar su disposición de mesas y sillas para buscar la más adecuada y no conformarse con la que tiene. El análisis de los tamaños de grupo que conforman el mercado y la mejor disposición de mesas y sillas para rentabilizar el espacio disponible es un tema claro de investigación posterior en la cual también puede ser usado el simulador desarrollado.

- En el experimento efectuado se consideró la igualdad de probabilidades para la selección de platos por los clientes. Esa no es la realidad que debe existir en un restaurante. Si se conociera la preferencia del mercado por los distintos platos ofertados, la técnica descrita de Menu Engineering podría ser explotada en las acciones tácticas a recomendar. El simulador desarrollado permite la incorporación de esas preferencias directamente en los datos, pudiendo ampliarse en futuros experimentos.

\section{Bibliografía}

AMR Research Survey Report (2010). Revenue management: A key to profitability for the high-tech industry.

Bell, D.; Raab, C.; Hertzman, J. y K. Mayer (2006). "Activity - Based costing Menu Engineering". Journal of Foodservice Business Research. Vol. 9 (1). 
Bitran, Gabriel y René Caldentey (2002). "An Overview of Pricing Models for Revenue Management". Massachusetts: MIT, Sloan School of Management y Nueva York: Universidad de Nueva York, Stern School of Business.

Brann, David M. y Beth C. Kulick (2002). "Simulation of restaurant operations using the restaurant modeling studio". Winter Simulation Conference.

Cross, Robert G.; Higbie, Jon A. y Zachary N. Cross (2011). "Milestone in the application of analytical pricing and revenue management". Journal of Revenue and Pricing Management. Vol. 10.

Kasavana, M. D. Smith (1990). Menu Engineering - A practical guide to menu analysis. Okemos MI: Hospitality Publications, Inc.

Kimes, Sheryl E. (2008). The role of technology in restaurant revenue management. Cornell Hospitality Quarterly.

LeBrutto, S.; Ashley, R. y W. Quain (1997). "Using the contribution margin aspect of Menu Engineering to enhance financial results". International Journal of Contemporary Hospitality Management 9(4), 161-167.

Puig-Durán Fresco, Jorge (2006). Certificación y modelos de calidad en hostelería y restauración. Madrid: Ediciones Diaz de Santos.

Talluri, Kalyan T. y Garret J. Van Ryzin (2004). The theory and practice of revenue management. Nueva York: Springer.

Thompson, Gary M. y Heeju Sohn (2008). "Accurately estimating time-based restaurant revenues using". Cornell Hospitality Report. Vol. 8. 